\title{
Análisis glotopolítico de manuales escolares de portugués en Argentina y de español en Brasil: tensiones en la representación de los paradigmas verbales y pronominales
}

Virginia Irene Rubio Scola ${ }^{a}$

\begin{abstract}
Resumen
En el presente artículo abordamos el encuentro entre el español y el portugués a través de manuales de español en el ensino médio brasileño y manuales de portugués en la escuela secundaria argentina. A partir de las políticas lingüísticas brasileña y argentina sobre la enseñanza de la lengua del país vecino en la escuela secundaria, realizamos un análisis glotopolítico de los libros didácticos que circularon en la escuela media durante el período 2003-2015. Con el objetivo de comprender las ideologías lingüísticas en disputa al sistematizar ambas lenguas, elaboramos un análisis comparativo sobre cómo se abordan las personas del discurso en los libros didácticos. Primero reseñamos diferentes estudios sobre las representaciones de ambas lenguas como lenguas extranjeras en Brasil y Argentina y sobre las asimetrías en relación con el uso de
\end{abstract}

\footnotetext{
a Instituto Rosario de Investigaciones en Ciencias de la Educación-Universidad Nacional de Rosario (IRICE-CONICET) Universidad Nacional de Rosario (UNR), Rosario, Argentina.

E-mail: virginrubio@gmail.com
}

\section{Cómo citar:}

Rubio Scola, V. I. Análisis glotopolítico de manuales escolares de portugués en Argentina y de español en Brasil: tensiones en la representación de los paradigmas verbales y pronominales. Gragoatá, Niterói, v.26, n.54, p. 405-435, 2021. <https:// doi.org/10.22409/gragoata.v26i54.46378> 
los pronombres y conjugaciones verbales. Luego analizamos de forma contrastiva los libros didácticos que circularon en Argentina y las cinco colecciones aprobadas por el Programa Nacional do Livro Didático de Brasil de 2012 y 2015. En conclusión, identificamos que dos políticas lingüísticas opuestas (dirigista en el caso de Brasil y liberal en el caso de Argentina) en las medidas sobre la confección de libros didácticos tuvieron diferentes repercusiones en las formas de representar a ambas lenguas. En lineas generales, las representaciones del español consistieron en una lengua rica y diversa; en cambio, el portugués fue representado como una lengua más homogénea atada a una tradición prescriptiva.

Palabras claves: Glotopolítica. Mercosur. Lenguas extranjeras. Escuela secundaria. Manuales escolares.

\section{Introducción}

El presente trabajo parte de mi tesis doctoral (2020) sobre la enseñanza del portugués en Argentina y del español en Brasil en la enseñanza media durante el período 20032015. En ese período se consolidaron iniciativas glotopolíticas de integración regional que llevaron a la sanción de las leyes 11.161/2005 en Brasil y 26.468/2009 en Argentina. Estas leyes instauraban la lengua respectiva del país vecino como lengua de oferta curricular obligatoria para las escuelas, pero facultativas para el alumno, en el nivel medio. En la tesis de doctorado estudiamos los diferentes impactos que tuvieron esas leyes en Brasil y Argentina en relación con los diseños curriculares y materiales didácticos. En el siguiente artículo nos centraremos en el estudio de las representaciones del español y del portugués en los manuales que circularon en las escuelas. Más precisamente analizaremos de qué forma se encuentran representadas las variedades de español y de portugués en los paradigmas pronominales y verbales (autoridad lingüísticogramatical), en las consignas (autoridad pedagógica) y en los textos que muestran los usos (modelos de uso).

Como decíamos, el impacto de las leyes sobre la oferta de la lengua del país vecino fue diferente en cada país. En Brasil tuvo consecuencias mayores en políticas públicas que intervinieron en la confección de manuales escolares por medio 
${ }^{1}$ En este contexto, se sancionó la ley de español estadual en Rio Grande do Sul en el año 2018. Disponible en: <https:// gauchazh.clicrbs.com. br/educacao-e-emprego/ noticia/2018/08/comissaoda-assembleia-aprova-queensino-de-espanhol-sejaobrigatorio-nas-escolascjku0aei501cr01n0aaed3c1w. html> Último acceso: 29 jul. 2020. Para seguir el movimiento por Estados consultar <https:// www.facebook.com/ ficaespanhol/> Último acceso: 29 jul. 2020. del Programa Nacional do Livro Didático en el ensino fundamental y en el ensino médio (en adelante, PNLD). Este programa seleccionó y distribuyó gratuitamente libros didácticos de español en escuelas públicas de Brasil. Para el ensino médio entre los años 2012 y 2018 hubo tres convocatorias: 2012, 2015 y 2018. A pesar de estas medidas, la ley nacional de español solo estuvo vigente hasta la reforma educativa impulsada con la Medida Provisória $n^{\circ} 746 / 2016$ y consolidada, posteriormente, con la ley 13.415 de 2017. Sin embargo, gracias al movimiento \#ficaespanhol y al trabajo de concientización de docentes de español en Brasil junto con las universidades federales y la comunidad educativa, muchos Estados de Brasil han sancionado leyes estaduales de oferta obligatoria de español en las escuelas. ${ }^{1}$

En relación con los manuales escolares de español en Brasil, además de los manuales del PNLD, en el mercado editorial circula una gran cantidad de manuales de español para la enseñanza media (FERNÁNDEZ, 2018). En este estudio nos centraremos en los manuales de español de las convocatorias de los años 2012 y 2015 (El arte de leer, Sintesis, Enlaces y Cercanía Joven).

En Argentina, la ley de oferta obligatoria de portugués tuvo un impacto mucho menor en general, ya que no fue incluida como lengua obligatoria en los lineamientos nacionales y no hubo una política del Estado de confección de manuales para la escuela secundaria. Solamente se realizaron tres propuestas didácticas innovadoras de portugués: una por parte del Ministerio de Educación de Ciudad de Buenos Aires en 2009 y dos por parte del Ministerio de Educación de la Nación en 2010 y 2015. En el mercado editorial tampoco hubo una proliferación de manuales escolares. En 2015 se elaboró un único manual escolar destinado a la enseñanza secundaria (Péna Estrada) y se adaptaron al contexto escolar otros manuales orientados a un público adolescente (Português Dinâmico, 2011 y Tudo bem?, 2010). Según una encuesta que realizamos en noviembre de 2016, los docentes de portugués de escuelas secundarias, además de los manuales mencionados, también utilizaban manuales para adultos, como Novo Avenida Brasil (2008), Bem-vindo! (2009) y Brasil Intercultural (2013). Cabe señalar que la encuesta mostró un claro descontento ante la escasez de manuales disponibles para la enseñanza media y las/los docentes agregaron que solían no emplear un único manual sino que armaban sus 
propios materiales y combinaban contenidos de diferentes manuales.

Para este artículo, nos detendremos en el análisis de las representaciones sociolingüísticas vehiculadas en los manuales mencionados. Nos interesa abordar, desde una perspectiva glotopolítica, los recortes realizados por los manuales en relación con la diversidad lingüística. Con ese objetivo, nos centraremos en cómo son abordadas las personas del discurso, ya que se trata de una de las mayores dificultades en la enseñanza/aprendizaje de ambas lenguas. Esto se debe a que poseen diferentes variantes en función de las variedades de español y portugués.

\section{Las representaciones del español y del portugués como lenguas extranjeras}

Con el término "glotopolítica" se denominan, de una forma amplia, las acciones de la sociedad sobre el lenguaje, intencionadas o no, y, a su vez, se denomina con ese término el estudio de la dimensión política de estas acciones. Dentro de estas, que pueden ser de tipo muy variado, se encuentra la creación de instrumentos lingüísticos, como son gramáticas, diccionarios, materiales didácticos, manuales escolares. El análisis de los instrumentos lingüísticos se ha configurado como un campo importante dentro de los estudios glotopolíticos. Algunos estudios que retomaremos en nuestro análisis son los de Del Valle y Villa (2005), Arnoux y Del Valle (2010). Desde el punto de vista de estos estudios, las lenguas son constructos discursivos que como tales se encuentran en disputa y son atravesados por posicionamientos políticos más amplios que se reflejan en diferentes ideologías lingüísticas. Arnoux (2018) define las ideologías lingüísticas como un conjunto de representaciones sociolingüísticas que asocian objetos lingüísticos con valoraciones sociales. Estas dependen de las posiciones sociales y/o de los posicionamientos que los que las sostienen adoptan en los espacios en los que actúan. Según Bein (2005, p. 2), “El concepto de representación sociolingüística [es] una suerte de constructo ideológico interpuesto entre la praxis lingüística real y la conciencia social de esa praxis". Las representaciones sociolingüísticas son manifestaciones discursivas de ideologías lingüísticas. 
2 Unión de Naciones Sudamericanas (organismo creado en 2008 y disuelto en 2018).

${ }^{3}$ Comunidad de Estados Latinoamericanos y Caribeños (2010).

En nuestro caso, podemos pensar en la construcción discursiva que hacen los manuales sobre el español legítimo que debe ser enseñado en la escuela en Brasil y el portugués que debe enseñarse en Argentina. La necesidad de incluir estas lenguas en la enseñanza formal se justificó mediante diferentes argumentos. En Brasil, los fundamentos de la ley de español subrayaron la presencia del español en el mundo (RODRIGUES, 2010) y las Orientações Curriculares do Ensino Médio (en adelante, OCEM, 2006) mencionaron el Mercosur pero no se restringieron a esta región, sino que hicieron hincapié en la valoración de su diversidad. En cambio, los fundamentos de la ley argentina destacaron la integración y la ciudadanía regional, aunque, como mencionábamos, esto no se reflejó en los Núcleos de Aprendizajes Prioritarios (NAP) de 2012 (RUBIO SCOLA, 2019).

Así, esas lenguas se incluyeron en los diseños curriculares dentro de la disciplina Lenguas Extranjeras diferenciándolas de la disciplina Lengua o Lingua portuguesa, que abordaba el estudio de la lengua nacional de escolarización. Sin embargo, el portugués y el español, al ser significados también como lenguas de las integraciones regionales en auge en el período analizado (Mercosur, Unasur ${ }^{2}$ y CELAC $^{3}$ ) y siendo esas dos las lenguas mayoritarias de América Latina, no serían "tan extranjeras", ya que compartirían un espacio común. A su vez, la globalización visibilizó las dos grandes áreas idiomáticas, la hispanofonía y la lusofonía, con extensos territorios en el globo donde estas lenguas son habladas, independientemente de su estatus de lenguas nacionales $\mathrm{u}$ oficiales, rompiendo con las representaciones simbólicas de las fronteras estatales.

Diferentes estudios investigaron las representaciones sociolingüísticas del español y del portugués en el espacio de enunciación latinoamericano. En Rubio Scola (2019a) se identificó que en los manuales de portugués que circularon en Argentina predominó una representación fuertemente nacionalista de esta lengua, asociada al portugués de Brasil, reconociendo en diferentes grados su diversidad, o más bien algunas variedades. De los manuales mencionados, a excepción de Brasil Intercultural, todos presentan desde la introducción y las tapas una clara homogeneización monolingüe del territorio brasileño. Además, este último es representado a través de mapas que lo aíslan explícitamente de los restantes países de 
la región. En la figura 1 presentamos las tapas de los manuales publicados en Argentina; en los casos de Português Dinâmico (ANDRÉ; SANTA MARIA, 2011) y Pé na Estrada (RODRIGUES; SANTANA, 2015) se puede identificar el mapa de Brasil-isla que mencionábamos. En la tapa de Brasil Intercultural (SCHRÄGLE; MENDES, 2014), si bien las manos pintadas en diferentes colores buscan dar cuenta de un encuentro diverso, el título refiere exclusivamente al espacio nacional.

Figura 1 - Tapas de manuales de portugués publicados en Argentina
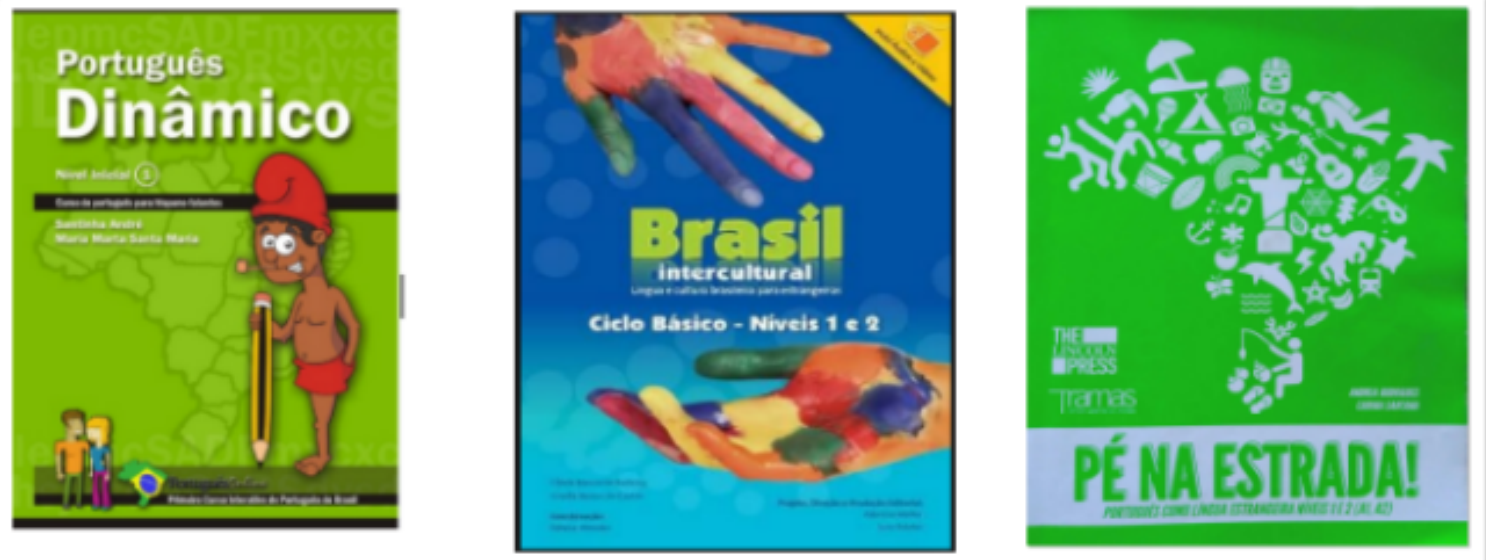

Fuente - Elaboración propia

En cambio, los manuales de español aprobados en las convocatorias del PNLD debieron seguir determinados lineamientos propios del proceso de selección; entre ellos, las OCEM (2006) y las Diretrizes Curriculares Nacionais. Las OCEM buscaron intervenir en las representaciones del español, dado que en la enseñanza de español en Brasil se le otorgaba prestigio a la variedad peninsular por tratarse de la variedad europea de origen, y también influía la presencia de España en el mercado brasileño, tanto en el editorial como en el educativo, con las diferentes sedes del Instituto Cervantes e intentos de acuerdos de este con el Ministerio de Educación brasileño (ABIO et al., 2010 y DEL VALLE; VILLA, 2005). De esta forma, las representaciones del español en Brasil no privilegiaban el vínculo de Brasil con Hispanoamérica; al contrario, las identidades latinoamericanas se encontraban invisibilizadas y desvalorizadas (PARAQUETT, 2009; LESSA, 
${ }^{4}$ Retomamos la distinción entre lengua fluida y lengua imaginaria propuesta por Orlandi y Souza (1988). La primera consiste en la lengua que puede ser observada en los procesos discursivos materializada en textos en determinados contextos de producción. En cambio, la segunda, la lengua imaginaria, es un objeto-ficción construido a través de modelos de estandarización; son las lenguas sistematizadas por instrumentos lingüísticos que hacen que pierdan su fluidez.
2013; LIMA, 2013). En respuesta a estos prejuicios sobre la lengua española, las OCEM se preocuparon por destacar la riqueza de la hispanofonía y su diversidad, sin reproducir la valoración hegemónica de la variedad peninsular en boga (RUBIO SCOLA, 2019b). Además, se buscó correr el foco de la reiterada pregunta sobre qué español enseñar a cómo enseñar esta lengua a brasileños; esto es, abordó la singularidad de esta lengua en el contexto brasileño. A diferencia de la confección de los manuales de portugués que respondieron a la oferta y la demanda del mercado editorial en Argentina, los manuales de español del PNLD fueron minuciosamente elegidos entre los que cumplían con los requisitos de evaluación, mostrando así una clara política lingüística de intervención sobre las representaciones de esta lengua.

Como decíamos, en las representaciones de estas dos lenguas intervienen varios factores. A partir de la pregunta "portugués de Brasil y ¿español de dónde?", Fanjul (2004) busca describir la variación lingüística de las dos lenguas en el espacio sudamericano según criterios objetivos y subjetivos. Para el caso de la lengua portuguesa, el autor afirma que se puede delimitar un portugués brasileño y un portugués europeo. Los criterios objetivos que definen dos normas de portugués se basan en estudios que muestran la variación estructural (serán retomados más adelante). Los criterios subjetivos reflejan la existencia de un "português do Brasil" institucionalizado y representado como "otro" frente al portugués de Portugal. Esto se refleja en las tapas y títulos de los manuales de portugués para extranjeros, que, si bien denominan a la lengua "portugués", la asocian con el territorio brasileño y difunden la variedad brasileña; agregamos que se trata de un ideal de la variedad culta brasileña, la lengua imaginaria ${ }^{4}$ denominada língua padrão.

Para el caso de la lengua española, Fanjul (2004) destaca que los criterios objetivos suelen cuestionar la generalización del sintagma "español de América" y resaltan que la delimitación de las variedades no coincide con la delimitación nacional. Para los criterios subjetivos, el autor afirma que la delimitación de las variedades se ha encontrado más vinculada con los centros de prestigio, resultando en estandarizaciones policéntricas; no obstante, agrega que siempre existieron actitudes valorativas nacionalistas y puristas. En la visión subjetiva del español, 
también influyen las políticas de área idiomática emprendidas por la Real Academia Española y las diferentes Asociaciones, que visibilizan la diversidad y heterogeneidad de la lengua pero, al mismo tiempo, buscan la representación de una lengua común, que se expande a nivel global a raíz de la ideología lingüística panhispánica (ARNOUX; DEL VALLE, 2010) o, más recientemente, del español global (LAURIA, 2019).

Adicionalmente es importante destacar lo que señala Lagares (2018) sobre los procesos de normatividad de ambas lenguas. Por un lado, el español tuvo su norma establecida por la RAE, que ganó prestigio y autoridad a pesar de resistencias, $\mathrm{y}$, posteriormente, la norma se estableció en conjunto con las academias hispanoamericanas. Por otro lado, el portugués tuvo su normatividad establecida por los Estados nacionales, fundamentalmente Brasil y Portugal. Si bien últimamente, o más bien en el período estudiado, hubo avances en relación con la gestión de la lengua a través de la Comunidad de Países de Lengua Portuguesa (en adelante CPLP) con un programa de elaboración de materiales didácticos, estas iniciativas no se vieron reflejadas en los manuales que circularon por las escuelas argentinas. En el presente estudio solamente nos centraremos en los libros didácticos, ya que las actividades propuestas por los ministerios, al ser cuadernillos complementarios, no presentan un tratamiento específico de las formas verbales y pronominales de persona, sino que tienen como objetivo presentar textos auténticos y las posibilidades que brindan las TICs para trabajar en el aula.

\section{Las personas del discurso en español y portugués}

Como mencionamos, nos interesa comprender en los manuales de qué forma se encuentra representada la diversidad del portugués y del español en el abordaje de las personas del discurso. Los trabajos de Benveniste (2008) sobre la enunciación muestran que las personas del discurso yo/tú y la no persona (exterior al plano discursivo) son referidas por medio de diferentes pronombres personales y por las flexiones verbales. El concepto de persona puede designar tanto a las personas del discurso como los rasgos de persona de la flexión verbal. En español como en portugués, la persona del discurso y la persona de la flexión verbal no se corresponden para 
determinados pronombres. Por ejemplo, você(s) y usted(es) refieren a la segunda persona del discurso pero se conjugan habitualmente con las formas verbales de la tercera persona.

Pese a que el español y el portugués pareciesen coincidir en los paradigmas de pronombres personales, el portugués brasileño se distingue en gran medida del español y de otras lenguas romances en el uso de estas formas. El portugués brasileño tiende mayoritariamente a indicar la persona del discurso con pronombres personales rectos, dada la pérdida de flexión verbal de esta variedad. Al contrario, el español suele elidir los pronombres personales sujeto debido a la marcada flexión verbal y usa en mayor cantidad formas pronominales que sustituyen los complementos del verbo, los clíticos. Las formas pronominales sujeto del español indican contraste, cambio del centro de atención y suelen tener casi exclusivamente un referente humano o humanizado (FANJUL, 2014). Esta diferencia entre el portugués de Brasil y el español fue estudiada por González (1994) como una asimetría entre las lenguas y es retomada por diferentes investigaciones (entre ellas, CELADA, 2002; GONZÁLEZ, 2008; FANJUL, 2014).

Las variedades de portugués de prestigio de los centros urbanos de San Pablo, Río de Janeiro y Minas Gerais, redujeron el paradigma tradicional de seis formas verbales, coincidentes con seis formas pronominales, a cuatro o incluso a tres. $T u$ ha sido sustituido mayoritariamente por você, en estas zonas, y vós por vocês, en todo Brasil (exceptuando géneros jurídicos). Você y vocês adoptan las formas verbales de tercera del singular y plural, respectivamente. Si sumamos la sustitución, muy generalizada de nós por a gente (PERINI, 2010; BAGNO, 2011), que también adopta la tercera persona verbal, resulta un paradigma verbal reducido a tres formas: primera persona del singular y tercera del singular y plural. Incluso en muchas regiones de Brasil en donde se emplea el pronombre $\boldsymbol{t} u$, se lo conjuga con la desinencia de la tercera singular. Por ejemplo, si conjugamos el verbo ir en pretérito perfecto las formas verbales son las siguientes: “Eu fui (primera del singular), vocêf tu/a gente/ele/ela foi (tercera del singular), vocês/eles/elas foram (tercera del plural)".

Además de las formas você y a gente, que se conjugan en la tercera persona singular, se agregan las formas o senhor/a senhora, que designan la segunda persona singular para el 
tratamiento de respeto o distancia ("o senhor foi") y el verbo morfológicamente se conjuga en tercera persona singular. Adicionalmente, la tercera persona de la conjugación verbal puede, a través del pronombre $a$ gente, remitir a la primera persona singular con el sentido de "uno". Así, en portugués brasileño, la forma verbal de tercera persona singular es polisémica y puede referirse tanto a las dos personas del plano discursivo como a la no-persona. Por lo tanto, el uso de los pronombres sujeto es fundamental para marcar cuál es la persona del discurso y el grado de formalidad o distancia.

Adicionalmente, el debilitamiento de la distinción entre personas en la flexión verbal del portugués brasileño repercutió en una mayor presencia de pronombres sujeto que pasaron a funcionar como complementos verbales, sobre todo los de tercera persona del singular ele/ela (GALVES, 1985). A pesar de que los usos de estas formas respondan a la lengua de Brasil en su variedad culta, no son reconocidas como "correctas" por las gramáticas prescriptivas. De esta manera, para que los manuales de portugués puedan reflejar "la lengua tal cual es", como lo plantean en sus introducciones y en sus métodos didácticos, deberían oponerse a estas gramáticas. En nuestro análisis veremos que los manuales mantienen esta tradición prescriptiva y por ello las muestras de uso muchas veces se contradicen con los cuadros pronominales y verbales, ya que sistematizan una norma imaginaria y se pretende mostrar los usos de una lengua más fluida.

En español, las personas del plano discursivo se pueden expresar de diferentes formas en función de las variedades. Para la segunda persona, excepto en los lugares en los que el voseo está instituido, la forma tú y su respectiva flexión verbal de segunda persona singular designan el tratamiento de confianza (RAE, 2009). Esta forma se ha ido generalizando y terminó ocupando usos que antes le correspondían a la forma usted, sobre todo en zonas urbanas. Lo mismo sucedió con la forma vos en las zonas voseantes. Usted es la forma generalizada de respeto o distancia en la que coinciden los hispanohablantes. No sucede lo mismo con el plural ustedes, de uso generalizado en los países hispanohablantes para referirse a la segunda persona plural del discurso, sin distinguir respeto o confianza, excepto en el español peninsular, donde ustedes es utilizado como tratamiento de respeto (como plural de 
"usted") y vosotros para el tratamiento de confianza. Usted y ustedes interpelan la segunda persona del discurso, pero requieren la flexión verbal de la tercera persona. En cambio, la forma vosotros hace coincidir la persona del discurso con la flexión verbal tradicional de segunda plural. De esta manera, al conservar el uso de vosotros, el español peninsular hegemónico es la única variedad en la que coinciden las seis flexiones verbales tradicionales con las personas expresadas por los pronombres personales, excepto usted y ustedes, que son exclusivamente de uso formal. En consecuencia, veremos que esto es un problema para los manuales de español, ya que se encuentran confrontados entre mantener las seis formas tradicionales con vosotros para la segunda persona plural o incluir ustedes como segunda persona del plural siendo que requiere la forma verbal de tercera del plural. Además, esto se complejiza con la incorporación del voseo cuando tiene su flexión propia.

Tabla 1 - Cuadro comparado de las formas verbales en portugués padrão, portugués brasileño, español peninsular y español americano ${ }^{5}$

\begin{tabular}{|c|c|c|c|}
\hline Português padrão & $\begin{array}{l}\text { Portugués } \\
\text { brasileño }\end{array}$ & $\begin{array}{l}\text { Español } \\
\text { peninsular }\end{array}$ & Español americano \\
\hline Eu falo & Eu falo & Hablo & Hablo \\
\hline Tu falas & \multirow{3}{*}{$\begin{array}{l}\text { Você (tu) } \\
\text { Ele/Ela fala } \\
\text { A gente } \\
\text { (Nós falamos) }\end{array}$} & Hablas & Hablas/ (vos) Hablás \\
\hline Ele/ela fala & & Habla & Habla \\
\hline Nós falamos & & Hablamos & Hablamos \\
\hline Vós falais & \multirow{2}{*}{$\begin{array}{l}\text { Vocês falam } \\
\text { Eles/Elas }\end{array}$} & Habláis & (Ustedes y ellos) Hablan \\
\hline Eles/elas falam & & Hablan & \\
\hline
\end{tabular}

${ }^{5}$ La presente tabla no busca homogeneizar las formas, sino mostrar cómo difieren ambas lenguas en suelo latinoamericano y en las variedades que tradicionalmente se han considerado como las más prestigiosas (el español peninsular y el português padrão).
Fuente: elaboración propia

Otra particularidad del portugués de Brasil es que el uso de você, ocupando el terreno de $t u$, llevó a que no hubiera diferencia en los índices de persona de caso oblicuo entre las formas que corresponden a la tercera persona del singular y las formas que corresponden a la segunda del singular (BAGNO, 2011). Así, te se usa sin distinción tanto a $t u$ como 
${ }^{6}$ Las zonas voseantes son el sur de México, algunas regiones de Centroamérica, Venezuela, Ecuador, zona andina de Colombia, norte y este de Bolivia, Argentina, Uruguay, Paraguay $\mathrm{y}$ algunas zonas de Chile.

${ }^{7}$ Flexión correspondiente a Uruguay, Honduras y otros países centroamericanos. La alternancia en el español uruguayo se da entre las formas pronominales, no en las verbales que mantienen la forma del voseo (Ibidem).

${ }^{8}$ Es el menos frecuente de los tres, se documenta en Bolivia, Norte de Perú, Costa y Sierra de Ecuador y la provincia de Santiago del Estero, en menor frecuencia en Tucumán (Ibidem). a você, por ejemplo, "Eu te vi ontem, mas você não me viu". Las gramáticas tradicionales, que describen la língua padrão, consideran la combinación de pronombres, como você-te, un desvío, un "error" o la descalifican como "mistura de tratamento" $\mathrm{y}$, por ende, recomiendan evitarla y mantener la uniformidad del tratamiento. Los libros didácticos de nuestro corpus, Bem-vindo! (PONCE et al., 2009) y Tudo Bem? (PONCE et al., 2010), proponen ejercicios de corrección que responden a esta prescripción; así, reflejan un abordaje purista y conservador de la lengua. La combinación de pronombres personales como forma propia de géneros discursivos con características más orales no es abordada en los manuales. Sin embargo, esta se encuentra presente en los textos que proponen los manuales como muestras de uso.

Para el caso del español, según se trate de variedades tuteantes o voseantes, existen diferentes variantes en el sistema pronominal. Como ya mencionamos, existe el uso de vosotros y el uso exclusivo de ustedes. Además, existen las diferentes formas verbales que puede adquirir el voseo y, en el caso de los pronombres clíticos, hay distintas realizaciones, el leísmo, loísmo y laísmo. La combinación de un pronombre con una flexión verbal correspondiente a otra persona existe en los diferentes tipos de voseo, el voseo ${ }^{6}$ flexivo pronominal ("vos tenés, vos tenís"); voseo flexivo no pronominal ("tú tenés o tú tenís") ${ }^{7}$; voseo no flexivo pronominal ("vos tienes") ${ }^{8}$ y voseo reverencial, “¿Juráis a Dios y a la Patria?” (RAE, 2009, 1261). Por otra parte, en el español voseante, el pronombre vos concuerda con la forma te, independientemente de que se construyan con verbos pronominales. El voseo reverencial es el único que adopta la forma os. Como veremos, la única forma de voseo presente en los libros es la forma flexiva pronominal oficializada en el español rioplatense.

La falta de atención al funcionamiento complejo de estas formas pronominales, además de acentuar la ilusión de transparencia entre el portugués brasileño y el español, puede conducir a grandes malentendidos. Por ejemplo, en el caso del español, cuando se omite el pronombre sujeto usted, la flexión verbal de la tercera persona y los clíticos correspondientes (se, le) designan formalidad. Por lo tanto, para marcar distancia o formalidad en el tratamiento interpersonal en español son 
suficientes las flexiones verbales o las formas clíticas de tercera (por ejemplo, "le adjunto los documentos"). Esto no sucede en el portugués brasileño porque la forma no marcada neutra o de confianza você requiere la flexión de tercera persona verbal, al igual que la forma de respeto o senhor/a senhora. Así, en el portugués brasileño es necesaria la presencia del pronombre sujeto para marcar formalidad o respeto.

Para el aprendiz hispanohablante - o argentino - de portugués, las formas verbales de tercera persona singular producen un efecto discursivo de respeto o distancia. Sin embargo, en el portugués brasileño, las formas verbales de tercera, cuando eliden el pronombre sujeto, pueden significar proximidad en el tratamiento y combinarse con un pronombre átono de segunda te (Como [você] está hoje? Te liguei ontem). Por lo tanto, para percibir estas diferencias de sentido en el momento de interpelar al otro es necesario distinguir criterios comunicativos y criterios de flexión verbal. Para el caso del portugués, esto también significaría reconocer una norma culta brasileña más próxima a la lengua fluida.

La lingua padrão, lengua de escolarización, y la lengua fluida del portugués brasileño generan en los aprendices brasileños representaciones del español como una lengua difícil, ya que el español en el caso de los pronombres se asemeja más a la lingua padrão. Celada (2002), desde una mirada discursiva y psicoanalítica, señala que el aprendiz brasileño, al encontrarse con lo real de la lengua española (más parecida con la lengua ideal del portugués), activa la memoria de una violencia simbólica generada por la diglosia entre la lengua materna fluida y la lengua de escolarización, lengua imaginaria. Esto también lleva a una representación del español como lengua correcta, formal y difícil, sobre todo por la gran presencia de las formas clíticas, marca de la lengua imaginaria correcta del portugués. En contraposición, para el aprendiz argentino el portugués brasileño estaría más asociado a la informalidad (CELADA, 2010), que algunos libros didácticos de portugués suelen reproducir; por ejemplo, Tudo bem? afirma que el portugués de Brasil no suele distinguir formalidad de informalidad y generaliza el uso de você. 


\section{Análisis de los manuales de portugués que circulan en Argentina}

En los seis libros didácticos analizados, la voz pedagógica de las consignas interpela al alumno en segunda persona del singular con la forma você combinada con las formas pronominales de tercera persona se/lhe. En menor medida, algunas consignas son en plural, vocês. De esta forma, el uso de você se instituye en los manuales como forma legítima propia de la variedad brasileña para interpelar al aprendiz. El uso generalizado de este pronombre en los manuales acompaña los sentidos nacionalistas y homogeneizadores que hemos mencionado en la introducción.

Respecto de los cuadros de conjugaciones, los diferentes manuales en sus unidades adoptan criterios disímiles para organizar el paradigma de las formas pronominales y las flexiones verbales, como vemos en la Tabla 2.

Tabla 2 - Paradigma pronominal y flexiones verbales en los manuales de portugués en Argentina

\begin{tabular}{|c|c|c|c|c|c|}
\hline $\begin{array}{l}\text { Bem-vindo! } \\
\text { (2009) }\end{array}$ & $\begin{array}{l}\text { Tudo } \\
\text { Bem? } \\
\text { (2010) }\end{array}$ & $\begin{array}{l}\text { Novo Av Brasil } \\
\text { (1991) }\end{array}$ & $\begin{array}{l}\text { Português } \\
\text { Dinámico (2011) }\end{array}$ & $\begin{array}{l}\text { Brasil } \\
\text { Intercultural } \\
(2013) \\
\end{array}$ & $\begin{array}{l}\text { Pé na Estrada } \\
\text { (2015) }\end{array}$ \\
\hline $\mathrm{Eu}$ & $\mathrm{Eu}$ & \multirow{2}{*}{$\mathrm{Eu}$} & \multirow{2}{*}{$\mathrm{Eu}$} & $\mathrm{Eu}$ & $\mathrm{Eu}$ \\
\hline Você & Você & & & Você & Você/O senhor \\
\hline Ele/Ela & Ele/Ela & & Ele/Você/ & Ele/Ela & Ele/Ela \\
\hline Nós & Nós & Você/Ele/Ela & $\begin{array}{l}\text { O senhor, } \\
\text { A gente }\end{array}$ & A gente & A gente \\
\hline Vocês & Vocês & Nós & Nós & Nós & Nós \\
\hline \multirow[t]{2}{*}{ Eles/Elas } & Eles/Elas & Vocês/Eles/Elas & $\begin{array}{l}\text { Eles, Vocês, } \\
\text { Os senhores, } \\
\text { As pessoas }\end{array}$ & Vocês & $\begin{array}{l}\text { Vocês/ os } \\
\text { senhores }\end{array}$ \\
\hline & & & & Eles/Elas & Eles/Elas \\
\hline Tu e Vós & Tu e Vós & & & $\mathrm{Tu}$ & \\
\hline
\end{tabular}

Fuente: elaboración propia

Sobre la base de la Tabla 2, podemos identificar tres criterios en las disposiciones de los paradigmas pronominales y verbales: 
1. un paradigma tradicional de seis personas basado en un criterio comunicativo ( $\boldsymbol{t} \boldsymbol{u}$ y vós considerados por separado) adoptado por Bem-vindo! y Tudo Bem?;

2. un paradigma de cuatro personas organizado en base a las formas correspondientes a la flexión verbal. De este modo, la flexión verbal de tercera persona singular agrupa a você y ele/ela, y de igual forma la tercera persona del plural. $T \boldsymbol{u}$ no es contemplado. Este es el caso de Novo Avenida Brasil y Português Dinâmico. Este último también agrega la primera persona del plural a gente y las formas de respeto o senhor, $a$ senhora a la flexión de tercera persona singular;

3. un paradigma de siete personas que considera las formas de la segunda persona plural, a gente y nós, como dos entradas distintas (cuando incorpora la forma $\boldsymbol{t} \boldsymbol{u}$ lo hace por separado del paradigma). Es el modelo de Brasil Intercultural y Pé na Estrada.

El modelo 2 se basa exclusivamente en el criterio formal de la flexión verbal. Los otros dos privilegian la organización del cuadro en función de criterios comunicativos. El modelo 3 se rige por este criterio pero se vuelve confuso al presentar dos entradas de primera persona plural.

El sistema pronominal, en general, es representado en los libros didácticos de portugués de forma homogénea para todo el territorio, salvo en el abordaje de la segunda persona del discurso, ya que se suele visibilizar el uso de $\boldsymbol{t} \boldsymbol{u}$ como variante de você para Estados de las regiones Sur, Nordeste y Norte. Como vemos en la Tabla 2, no todos los manuales incorporan esta forma al paradigma y cuando la incorporan lo hacen de forma separada. En el contenido de las unidades, el uso de $\boldsymbol{t} \boldsymbol{u}$ suele ser representado como una excepción, que generalmente se registra al lado del paradigma de conjugación, bajo una etiqueta de advertencia: "Lembre-se" (Novo Avenida Brasil), "Atenção" (Pé na estrada). De esta forma, se busca producir un efecto de homogeneidad de la lengua en relación con las formas de tratamiento y se minimizan las variedades a variantes puntuales. La variación de las formas pronominales es explicada en Novo Avenida Brasil con la siguiente afirmación: 
"[tu] é usado em Portugal e em algumas regiões do Brasil" (LIMA et al., 2008, p. 12) y en Pé na Estrada leemos:

ATENÇÃO: Em Portugal ainda se usam os pronomes TU e VÓS no lugar de VOCÊ e VOCÊS.

No Brasil, na região Sul, você pode chegar a ouvir as pessoas dizendo o pronome TU. Mas o mais comum é a utilização de VOCÊ e VOCÊS. Também podemos usar os pronomes NÓS e A GENTE. Eles possuem a mesma finalidade, mas o NÓS é mais formal e o A GENTE é informal. Além disso, temos que ficar atentos às terminações dos verbos! (RODRIGUES; SANTANA, 2015, p. 18, mayúsculas originales)

En la cita, la expresión "você pode chegar a ouvir" minimiza la presencia de $\boldsymbol{t} u$ además de reducirla a la región Sur, cuando se trata de una forma ampliamente generalizada en las regiones del Norte y Noreste de Brasil. Se señala "lo más común" y se ubica a $t u$ en el lugar de la excepción. También, en la cita, se diferencia nós de a gente, recurriendo a la formalidad/informalidad, cuando el uso de a gente en Brasil es cada vez más generalizado en la oralidad. La afirmación que "Em Portugal ainda se usam os pronomes TUe VÓS no lugar de $V O C \hat{E} e$ VOC $\hat{E} S^{\prime \prime}$ es muy generalizadora, ya que en Portugal se emplean, con valores diferentes que en Brasil, los pronombres você y vocês. En esta última cita, podemos reconocer que la referencia matricial a partir de la cual se explica la variación se encuentra en el portugués de Brasil, al afirmar que $\boldsymbol{t} u$ y vós, formas atribuidas al portugués europeo, se usan "en el lugar de" você y vocês y no al revés. Así, se refuerza la binorma del portugués y, a diferencia de lo que sucede con las variedades hispanohablante, la norma brasileña (ex-colonia) es asumida como referencia para explicar los usos del portugués de Portugal.

De esta misma forma, es abordado el uso de $\boldsymbol{t} u$ en el paradigma de los pronombres sujetos en Tudo Bem? y Português Dinâmico. Ambos manuales solo mencionan a $\boldsymbol{t} u$ y você en las sistematizaciones y, en el caso de Tudo Bem?, en una ejercitación específica sobre conjugaciones de verbos en $\boldsymbol{t} \boldsymbol{u}$ y $\boldsymbol{v}$ ós al final del libro. Los dos manuales no presentan textos que muestren esos usos ni las diferentes conjugaciones con la que se conjuga el pronombre $\boldsymbol{t} \boldsymbol{u}$ según las diferentes regiones de Brasil. En este sentido, Brasil Intercultural en su tercer volumen (Ciclo Avançado) tematiza estos usos como desviaciones de la norma. 
O pronome TU é usado em alguns estados brasileiros, não em todos, e na grande maioria dos lugares onde é usado não obedece à conjugação estabelecida pela norma culta, e sim, usa a conjugação do pronome VOCÊ (SCHRÄGLE; MENDES, 2014, p. 85 , bastardillas nuestras, mayúsculas originales)

No se especifica en cuáles Estados brasileños se usa la forma $\boldsymbol{t} \boldsymbol{u}$ pero, a diferencia de los otros manuales, explica cómo se emplea la forma $t u$ en varias regiones de Brasil, "desobedientes a la norma culta". Además, el manual expone la diferencia entre "la norma culta según la perspectiva prescriptiva" y las variaciones de la "lengua culta según la perspectiva del lenguaje en uso" (SCHRÄGLE; MENDES, 2014, p. 85). Así, se visibilizan las dos normas cultas: por un lado, la norma culta correspondiente a la lengua imaginaria y, por otro lado, la norma culta de la lengua fluida, "desobediente". A diferencia de los otros manuales, Brasil Intercultural busca visibilizar el uso de $\boldsymbol{t} \boldsymbol{u}$ conjugado con la flexión de tercera persona singular y presenta ejemplos tuteantes de textos en portugués brasileño, como será analizado con los pronombres posesivos.

Estas incongruencias en las disposiciones de los cuadros y de los pronombres personales del portugués brasileño muestran la tensión no resuelta entre la gramática de la lengua ideal y la lengua efectivamente hablada en Brasil. Tudo Bem? y Português Dinâmico son manuales elaborados para un público adolescente y Pé na Estrada, como mencionamos al comienzo, es el único manual elaborado en Argentina en un contexto pedagógico de una escuela secundaria. En el tratamiento de los pronombres, no hay diferencias con el tratamiento que hacen Novo Avenida Brasil y Bem-vindo! que son manuales dirigidos a adultos extranjeros. Tampoco hay una preocupación por contrastar los usos de estas formas con el español o con otras lenguas. La falta de textos auténticos que den cuenta de la diversidad de uso de estos pronombres y la simplificación de la sistematización de estas formas reproduce una representación del portugués brasileño como una lengua homogénea reforzando una ideología lingüística nacionalista. Brasil Intercultural, en cambio, busca cuestionar esta representación al visibilizar una norma que no responde al portugués considerado "correcto". 
Con relación a los paradigmas de pronombres clíticos, posesivos y las combinaciones de pronombres, lo manuales analizados son aún más conservadores a excepción de Brasil Intercultural. En Bem-vindo!, Tudo bem? y Português Dinâmico, las formas correspondientes a $t \boldsymbol{t u}$, te y teu figuran como única entrada de segunda singular. En los casos de Português Dinâmico y de Tudo Bem?, manuales para adolescentes, você y sus correspondientes formas clíticas de segunda o de tercera no son contempladas. Este borramiento hace que el paradigma representado esté completamente distanciado de las muestras de uso que figuran en los manuales, sobre todo los textos dialogados en donde predomina você y las correspondientes formas de tercera. En el caso de Pé na Estrada, las formas correspondientes a $t \boldsymbol{u}$ no figuran en el paradigma de posesivos, a pesar de que el cuadro se encuentre en la unidad que tematiza la región Sur, en donde su uso es ampliamente generalizado.

Brasil Intercultural incluye los posesivos correspondientes a $\boldsymbol{t} \boldsymbol{u}$ separados del paradigma y você comparte la entrada de ele/ela, formas a las que se les adjudican los posesivos de tercera singular, seu(s) y sua(s). No obstante, en los textos de las unidades se combinan los pronombres você y teu, como en la canción "O tempo não para" de la página 99 del libro del profesor: "Mas se você achar que eu tô derrotado (...) A tua piscina tá cheia de rato/Tuas ideias não correspondem aos fatos". Con la sistematización de las formas clíticas sucede algo similar. En los textos de las unidades, predomina el uso de você con las respectivas formas de tercera persona $(s e, o, a, l h e)$, aunque en diferentes textos se producen combinaciones de você con te. No obstante, Brasil Intercultural es el único manual que considera los casos en que los clíticos pueden ser reemplazados por pronombres sujetos. En el volumen 3 de Brasil Intercultural, se exponen dos paradigmas de pronombres clíticos: el aceptado por la gramática prescriptiva y el "modificado de acuerdo con variaciones de la norma culta, en la perspectiva de la lengua en uso" (SCHRÄGLE; MENDES, 2014, p. 85, traducción nuestra). Agrega que los pronombres você, vocês y a gente pueden funcionar como formas sujeto, objeto directo y objeto indirecto (precedidos de la preposición para).

Para el aprendiz argentino o hispanohablante, las disposiciones de los paradigmas de la gramática prescriptiva, 
que no coinciden con los usos brasileños, tienden a reforzar la idea de transparencia entre las lenguas, como si los pronombres en español y en portugués de Brasil se pudieran traducir de forma biunívoca y tuviesen el mismo funcionamiento en el uso. Como identificamos anteriormente, los criterios suelen ser muy diversos inlcuso a lo largo de un mismo manual. Las diferentes decisiones sobre cómo organizar el paradigma pronominal y el verbal muestran tensiones y vacilaciones para definir las formas pronominales del portugués de Brasil. Entendemos que es el resultado de la incompatibilidad entre explicar el uso de las formas sobre la base de una norma correspondiente a la lengua imaginaria brasileña y buscar ser fieles al "portugués efectivamente hablado en Brasil" a partir de textos "auténticos". De esta manera, los manuales dejan explícita la diglosia entre el uso de los pronombres en los textos mostrados y la sistematización que proponen.

\section{Análisis de los los manuales de español elaborados en Brasil}

En los manuales de español, la voz pedagógica de las consignas interpela al alumno por medio de las formas correspondientes a tú y, en menor cantidad, se pluraliza en ustedes. Respecto de la sistematización lingüística en las colecciones aprobadas por el PNLD 2012, los cuadros con los paradigmas de las formas pronominales y sus correspondientes flexiones verbales se rigen por criterios muy similares (Tabla 3). Como podemos observar, todos los paradigmas presentan las seis personas del discurso organizadas según la flexión verbal. El arte de leer omite los pronombres personales sujeto y, de esta manera, destaca la marcada flexión verbal del español. Sintesis (MARTIN, 2010) y Enlaces (OSMAN et al., 2010)juntan la segunda persona singular y plural del discurso, usted(es), con la tercera persona el(los)/ella(s). A excepción de usted(es), predomina un criterio comunicativo en la organización del paradigma. En cambio, en las colecciones aprobadas en 2015, se complejiza la organización de las personas, ya que incluyen el voseo. 
Tabla 3 - Paradigma pronominal y flexiones verbales en los manuales de español en Brasil PNLD 2012 y 2015, negritas nuestras

\begin{tabular}{|c|c|c|c|c|}
\hline $\begin{array}{l}\text { El arte } \\
\text { de leer } \\
(2012)\end{array}$ & $\begin{array}{l}\text { Sintesis } \\
(2012)\end{array}$ & $\begin{array}{l}\text { Enlaces } \\
(2012)\end{array}$ & $\begin{array}{l}\text { Enlaces } \\
(2015)\end{array}$ & $\begin{array}{l}\text { Cercanía } \\
\text { Joven (2015) }\end{array}$ \\
\hline $\mathrm{o}$ & yo & yo & yo & yo \\
\hline as & tú & tú & tú & tú/vos \\
\hline a & él/ella/usted & él/ella/usted & vos & $\begin{array}{l}\text { él/ella, } \\
\text { usted }\end{array}$ \\
\hline amos & $\begin{array}{l}\text { nosotros/ } \\
\text { nosotras }\end{array}$ & nosotros/as & él/ella, usted & nosotros/as \\
\hline áis & $\begin{array}{l}\text { vosotros/ } \\
\text { vosotras }\end{array}$ & vosotros/as & nosotros/as & vosotros/as \\
\hline \multirow[t]{2}{*}{ an } & $\begin{array}{l}\text { ellos/ellas/ } \\
\text { ustedes }\end{array}$ & $\begin{array}{l}\text { ellos/ellas/ } \\
\text { ustedes }\end{array}$ & vosotros/as & $\begin{array}{l}\text { ellos/as, } \\
\text { ustedes }\end{array}$ \\
\hline & & & $\begin{array}{l}\text { ellos/as, } \\
\text { ustedes }\end{array}$ & \\
\hline
\end{tabular}

Fuente: elaboración propia

Como vemos en la Tabla 3, Enlaces 2015 opta por incluir vos como una nueva entrada del paradigma, que pasa a estar constituido por siete personas. De esta forma, mantiene el criterio de la flexión verbal y se pierde el criterio comunicativo de seis personas del discurso. Cercanía Joven opta por adicionar vos como alternativa de tú, manteniendo el criterio comunicativo (COIMBRA et al, 2013). Así, vos comparte con tú la misma entrada respondiendo a un criterio comunicativo, pero usted(es) permanece en la entrada de tercera, según el criterio de la flexión verbal. Todas las colecciones optan por mantener vosotros/as como única forma para la entrada correspondiente a la segunda persona del plural. De este modo, una forma minoritaria de la hispanofonía adquiere una posición destacada con respecto a las otras formas.

A diferencia del escaso tratamiento específico que se les concede a los pronombres y flexiones verbales en los manuales de portugués, las colecciones de español le dedican en el primer volumen una unidad completa ("La lengua es útil para la comunicación" en El Arte de leer; "Quién es" en Sintesis, "Del tú al usted" en Enlaces) o un abordaje específico 
con explicaciones, ejercicios y ejemplos de uso (Cercanía Joven profundiza los pronombre personales en el anexo, "Chuleta Lingüística").

El arte de leer aborda el voseo a partir de la historieta argentina Gaturro, del dibujante Nik, y lo explica de la siguiente forma: "Este tratamiento es correspondiente al "tú" que usan los españoles y otros pueblos hispanohablantes. Al usar el voseo, hay que tener en cuenta que la sílaba fuerte es la última" (PICANÇO; VILLALBA, 2012, p. 33). En la página 47, se propone una actividad a partir de una tira de Mafalda, cuya consigna solicita que se sustituya la variedad voseante por la variedad peninsular, tomando a esta última como referencia: "¿Cómo hablarían Mafalda y Libertad si usasen el español de España?". Luego de ese ejercicio, se contrasta esta diferencia con las variedades del portugués y se llega a la conclusión de que "Las variantes regionales no son curiosidad lingüística de la cultura de cada pueblo" (PICANÇO; VILLALBA, 2012, p. 48). Podemos identificar la preocupación por mostrar la diversidad del español contemplando los usos y no como si fueran excepciones. No obstante, el español peninsular opera como variedad matriz que permite explicar las otras variedades. Otro ejemplo de esto, en el mismo libro, es la comparación de la variedad peninsular con la variedad de Asunción del Paraguay. En la misma unidad, después de presentar diferentes lecturas sobre las variedades de español y las implicaciones políticas del nombre de la lengua (español/castellano), el manual tematiza especialmente el castellano rioplatense a través de un texto de Wikipedia que señala la extensión y el prestigio de esta variedad, por ser hablada en grandes centros urbanos y difundida ampliamente en medios audiovisuales.

Desde el inicio, Sintesis (MARTIN, 2010), propone sensibilizar al alumno con las diferentes variedades al presentar diferentes diálogos ficticios para abordar el género "presentación personal" en registros formales e informales. Los diálogos adoptan variedades que pueden ser inferidas a partir de los audios o de las transcripciones en función del país de procedencia de los interlocutores. En los diálogos se emplean tú y usted marcando las diferencias de registro, sin incluir el voseo. Este es tematizado con diferentes historietas argentinas. En las explicaciones, el voseo no es abordado como exclusivo de Argentina, ya que se destacan los países en los 
que su uso tiende a ser generalizado y aquellos en los que convive con la forma tú. No obstante, todas las flexiones del voseo presentadas en el manual corresponden a la variedad rioplatense. Además, en la página 41, encontramos formas voseantes en un modelo de examen de ingreso a la universidad, ya que las consignas refieren a una tira de Mafalda. El voseo no solamente es tematizado en los manuales sino que también puede llegar a ser evaluado. Sin embargo, a lo largo de las unidades conviven paradigmas verbales que no contemplan el voseo inmediatamente al lado de historietas argentinas. Por ejemplo, en la página 47, el personaje de la historieta vosea, “Sabés qué es lo más importante que hay que hacer todas las mañanas antes de ir al colegio?", pero el cuadro de verbos no presenta la forma "te despertás", sino solamente "te despiertas".

Enlaces del PNLD 2012 es, entre los manuales de esa convocatoria, el que le asigna menor visibilidad al voseo. Uno de los pocos textos que incluyen el voseo es la historieta argentina Tute, con rasgos marcados de la variedad rioplatense, como es el prefijo "re-" para indicar intensidad y la presencia del pronombre vos. Sin embargo, cuando se tematizan las formas de tratamiento, no se aborda el voseo. Se visibilizan las variedades desde un abordaje más metalingüístico, dado que se presentan textos que tratan sobre las variedades o que, cuando emplean una forma regional, lo hacen entre comillas. En cambio, la reformulación de Enlaces aprobada en el PNLD 2015, como vimos, agrega el voseo en los cuadros de conjugación. Hace más énfasis en los usos de las variedades, visibilizando diálogos con usted para el tratamiento íntimo. Además, esta reedición reformula un cuadro contrastivo sobre las formas de tratamiento, que en la versión 2012 separaba los usos entre España e Hispanoamérica y los contrastaba con las formas brasileñas. En la nueva edición, la disposición de las formas visibiliza que esos territorios no consisten en espacios homogéneos ("España (la mayor parte)", "Hispanoamérica y España (Canarias y algunas zonas de Andalucía)", "Algunos países de Hispanoamérica").

Por último, Cercanía Joven también hace énfasis en la diversidad del español, a través de diferentes textos que muestran la variedad de la lengua española. En referencia a los pronombres personales, aclara que las formas usted y ustedes son válidas para el tratamiento formal y que se utiliza 
ustedes como variante de vosotros en Hispanoamérica. En la sección Chuleta Lingüística en el anexo del libro, se detalla el uso comunicativo de cada forma: quienes hablan (yo y nosotros), a quienes se habla (tú, vos, usted, vosotros, ustedes) y de quienes se habla (él, ella, ellos, ellas) (COIMBRA et al., 2013, p. 150). Las formas correspondientes al voseo de la variedad rioplatense se encuentran tanto en las sistematizaciones lingüísticas como en los textos que reflejan los usos y en los ejercicios creados.

A partir de este análisis, destacamos que, a diferencia de los manuales de portugués (salvo excepciones), los manuales de español no presentan un paradigma de corrección o centrado en la língua padrão, sino que hay una preocupación por mantener criterios que den cuenta de los usos y que sean coherentes con los textos de las actividades propuestas en las unidades. Se busca mostrar la heterogeneidad de la lengua española, como lo indican las orientaciones curriculares y las convocatorias de libros didácticos. Los manuales buscan sensibilizar al aprendiz sobre las diferentes variedades, aunque la variedad peninsular y la variedad rioplatense adquieran mayor visibilidad.

El paradigma de flexión verbal desataca la forma vosotros como única entrada correspondiente a la segunda persona plural, lo que permitiría hacer coincidir criterios comunicativos y de flexión verbal. Sin embargo, incluir a ustedes en la entrada de ellos y ellas e incluir el voseo en una entrada separada rompe con este criterio. La preocupación por dar cuenta de diferentes variedades en un mismo cuadro de conjugaciones es problemática porque reduce estas variedades a variantes, cuando en realidad se trata de sistemas pronominales diferentes. En consecuencia, podemos ver las tensiones de querer dar cuenta al mismo tiempo de los paradigmas peninsular y rioplatense. Por otra parte, la presencia de la variedad peninsular como variedad de referencia contrasta con lo que sucedía en los manuales de portugués en los que la variedad de Brasil marcaba la referencia ante la variedad europea.

\section{Consideraciones finales}

Los manuales que hemos analizado circularon en las escuelas secundarias brasileñas y argentinas en un periodo en el que, a nivel político, se buscaba consolidar una integración 
política e identitaria de la región. Nos propusimos pensar la relación dialéctica entre el proyecto regional, plasmado en dos gestiones de enseñanza de lengua distintas - la brasileña y la argentina -, y las representaciones sociolingüísticas de los libros didácticos a partir del análisis de los paradigmas pronominales y verbales.

La gestión del español en Brasil respondió a una fuerte presencia del Estado en la selección, compra y distribución de libros didácticos de forma centralizada y mediada por el discurso de la academia. En cambio, en Argentina la intervención del Estado fue más débil en la enseñanza de portugués, ya que los manuales de portugués lengua extranjera que circularon en las escuelas respondieron a una demanda de mercado asociada con el sector empresarial o con iniciativas privadas (institutos de idiomas, colegios privados).

Las intervenciones -o, más bien, la falta de intervención en el caso de Argentina- en la enseñanza de estas lenguas se reflejaron en las representaciones sociolingüísticas vehiculadas en nuestro corpus. En el caso de los manuales de portugués que circularon en Argentina, hemos identificado un fuerte nacionalismo lingüístico asociado a Brasil que se traduce en las homogeneizaciones de las formas pronominales y de las flexiones verbales, a través del pronombre você, dejando de lado los usos de tu con sentidos de excepción. En la representación de los pronombres, en especial de posesivos y clíticos, las propuestas didácticas de los manuales se encuentran desactualizadas y presentan varias inconsistencias, sobre todo al asumir en diferentes grados un abordaje conservador que sistematiza la lengua a partir de un discurso de la corrección. Este reproduce la diglosia entre la lengua imaginaria, língua padrão, y la lengua fluida. Identificamos algunos cuestionamientos de la gramática prescriptiva por parte de Brasil Intercultural pero esta sigue manteniendo sentidos de referencia. Sin embargo, mostraron la falta de un abordaje específico de los índices de persona para el aprendiz argentino. El hecho que se opte por la variedad de portugués de Brasil no necesariamente significa que se privilegie la integración con la región, ya que puede terminar reforzando ideologías nacionalistas que separan a Brasil de la región por tratarse del único país lusohablante. 
En cambio, las colecciones de español se preocuparon por subrayar la presencia del español en el mundo, su diversidad y heterogeneidad. No obstante, como destacamos, se visibilizó más la variedad rioplatense, que privilegió la relación bilateral con Argentina, aunque perduraron en las sistematizaciones y explicaciones que distinguen al español peninsular en tanto variedad matriz para describir las otras variedades.

En conclusión, el estudio muestra que con una política lingüística dirigista se puede intervenir en las representaciones sociolingüísticas, como fue el caso de los libros de español seleccionados por el PNLD. La política lingüística liberal dejó la producción de manuales a la merced del mercado editorial, distanciándose de una política lingüística acorde a las iniciativas regionales. Consideramos que es necesario realizar manuales que den cuenta de las singularidades de la enseñanza de estas lenguas como lenguas de integración de la región. Es importante trabajar en las representaciones sociolingüísticas desde una visión actualizada que contemple la diversidad de variedades de la región y de las otras lenguas con las que se encuentran en contacto en suelo latinoamericano.

\section{REFERENCIAS}

ABIO, Gonzalo; BAPTISTA, Lívia Márcia; O’KUINGHTTONS, Mónica; GONZÁLEZ, Neide Maia; IRALA, Valesca. A plataforma "AVE" do Instituto Cervantes: a posição analítica da COPESBRA. Linguasagem, 15a. edición, p. 1-13, octubrenoviembre-diciembre 2010. Disponible en: http://www. repositorio.ufc.br/bitstream/riufc/26424/1/2010_art_gabio. pdf. Acceso: 15 ago. 2020.

ANDRÉ Santinha.; SANTA MARIA, María M. Português dinâmico, Nível Inicial e Intermediário. Vicente López: SIM, 2011.

ARNOUX, Elvira. Apuntes para el estudio de las ideologías lingüísticas: en torno a las representaciones del inglés en la Argentina. Abehache - Revista de la Asociación Brasilera de Hispanistas, n. 13, p. 10-27, 2018. 
ARNOUX, Elvira; DEL VALLE, José. Las representaciones ideológicas del lenguaje. Discurso glotopolítico y panhispanismo. Spanish in Context. John Benjamins Publishing Company, 7, 1, p. 1-24, 2010.

BAGNO, Marcos. Gramática pedagógica do português brasileiro. San Pablo: Parábola, 2011.

BEIN, Roberto. Las lenguas como fetiche. In: PANESI, Jorge; SANTOS, Susana (ed.). Debates actuales: las teorías críticas de la literatura y la lingüística. Buenos Aires: Facultad de Filosofía y Letras, Universidad de Buenos Aires, 2005, s/p.

BENVENISTE, Émile. Problèmes de linguistique générale I, Paris: Gallimard, 2008.

CELADA, María Teresa. O espanhol para o brasileiro: uma língua singularmente estrangeira. 2015. $277 \mathrm{f}$. Tesis (Doctorado en Lingüística), Instituto de Estudios del Lenguaje, Universidad de Campinas, Campinas, 2002.

Memorias discursivas e imágenes de lenguas. Sobre el español en Brasil y el portugués en Brasil. In: CELADA, María T.; FANJUL, Adrián; NOTHSTEIN, Susana. Lenguas en un espacio de integración. Buenos Aires: Editorial Biblos, 2010, p. 209-235.

COIMBRA, Ludemila; CHAVES, Luiza Santana.; BARCIA, Pedro L. Cercanía Joven, San Pablo: Edições SM, 2013, vol. 1, 2, 3.

DEL VALLE, José; VILLA, Laura. Lenguas, naciones y multinacionales: las políticas de promoción del español en Brasil. Revista da Abralin, vol. 4, no 1 e 2, p. 197-230, 2005.

FANJUL, Adrián Pablo. Português brasileiro, espanhol de... onde? Analogias incertas. Letras $\mathcal{E}$ Letras. Uberlândia, 20 (1), jan./jun, p. 165-183, 2004.

Conhecendo assimetrias: a ocorrência de pronomes pessoais. In: FANJUL, Adrián González, Neide Maia (org.) Espanhol e português brasileiro: estudos comparados. São Paulo: Parábola, 2014, p. 29-50. 
FERNÁNDEZ, Gretel Eres. Políticas públicas para la (no) enseñanza de español en Brasil. In: MIRANDA, Cicero (Org.) La lengua española en Brasil: enseñanza, formación de profesores y resistencia. Brasilia: Consejería de Educación, 2018, p. 9-18.

GALVES, Charlotte. A sintaxe do português brasileiro. Cadernos de Linguística e Teoria da Literatura. $\mathrm{N}^{\circ}$ 13, p/ 31-50, 1985. Disponible en: http://www.periodicos.letras.ufmg.br/index. php/cltl/article/view/7204, Acceso en: 15 jun. 2018.

GONZÁLEZ, Neide Maia. "Cadê o pronome? O gato comeu" - Os pronomes pessoais na aquisicao/aprendisagem do espanhol por brasileiros adultos. 1994. 217 f. Tesis (Doctorado en Lingüística. Facultad de Filosofía, Letras y Ciencias Humanos, Universidad de San Pablo, San Pablo, 1994.

Portugués brasileño y español: lenguas inversamente asimétricas. In: CELADA, María T;; GONZÁLEZ, Neide (Coord. dossier). Gestos que trazan distinciones entre la lengua española y el portugués brasileño - Signos ELE, n. 1-2, p. 1-7, 2008.

LAURIA, Daniela. La institucionalización de la política lingüística panhispánica hoy - tensiones por la "marca España". Glotopol. n. 32, julio 2019, p 1-21.

LESSA, Giane da S. M. Memórias e identidades latinoamericanas invisíveis e silenciadas no ensino-aprendizagem de espanhol e o papel político do professor. In: ZOLIN-VESZ Fernando (org.). A (in)visibilidade da América Latina no ensino de espanhol. Campinas: Pontes Editores, 2013. p. 17-28.

LIMA, Emma; ROHRMANN, Lutz; ISHIHARA, Tokiko; IUNES, Samira A.; BERGWEILER, Cristian G., Novo Avenida Brasil: curso básico de português para estrangeiros. San Pablo: EPU, 2008.

LIMA, Lucielena M. de. Representações sobre América Latina em livros didáticos de língua espanhola, de história, de geografia e de sociologia. In: ZOLIN-VESZ, Fernando (org.). A (in)visibilidade da América Latina no ensino de espanhol. Campinas: Pontes Editores, 2013. p. 29-50. 
MARTIN, Ivan, Síntesis. San Pablo: Ática, 2010, vol. 1

ORLANDI, Eni; SOUZA, Tania C. C. de. A língua imaginária e a língua fluida: dois métodos de trabalho com a linguagem. In: ORLANDI, Eni (org.). Política lingüística na América Latina. Campinas: Pontes, 1988. p. 27-40.

OSMAN, Soraia; ELIAS, Neide; REIS, Priscila; IZQUIERDO, Sonia VALVERDE, Jenny. Enlaces: español para jóvenes brasileños 1. San Pablo: Macmillan, 2010.

Enlaces: español para jóvenes brasileños, San Pablo: Macmillan, 2013, vol. 1, 2 y 3

PARAQUETT, Márcia. Lingüística Aplicada, inclusión social y aprendizaje de español en contexto latinoamericano. Revista Nebrija de Lingüistica Aplicada a la Enseñanza de Lenguas. Número 6, Madrid: Nebrija Universidad, p. 1-23, 2009.

PERINI, Mário. Gramática do português brasileiro. San Pablo: Parábola, 2010.

PICANÇO, Deise C. de L.; VILLALBA, Terumi K. B., El arte de leer español, Curitiba: Base editorial, [2006] 2010, vol. 1.

PONCE, Maria H.; BURIM, Silvia A.; FLORISSI, Sussana. Bem-vindo! A língua portuguesa no mundo da comunicação, $8^{\circ}$ Edición, San Paulo: SBS, 2009. , Tudo Bem?, San Pablo: SBS, 2010, vol. 1

RAE. Nueva gramática de la lengua español: morfología y sintaxis I. Madrid: Espasa Libros, 2009.

RODRIGUES, Andrea; SANTANA, Carina. Pé na Estrada, Buenos Aires: Grupo Tramas, 2015.

RUBIO SCOLA, Virginia. Tensiones ideológicas en materiales didácticos de portugués en Argentina - globalización, lusofonía, Mercosur. Linguas e instrumentos lingüísticos. n. 43, Campinas: Unicamp, p. 237-258, 2019a, Disponible en: http:// www.revistalinguas.com/edicao43/capa\%20edicao43.pdf. Acceso en: 15 out. 2020. 
Representaciones del español en la escuela secundaria en Brasil. In: RIESTRA, Dora y MÚGICA, Nora (eds.). Estudios SAEL - Sociedad Argentina de Estudios Lingüísticos, Bahía Blanca: Ediuns y SAEL, p. 239-252, 2019b, Disponible en: http:// www.sael.com.ar/volumens-sael/. Acceso en: 15 out. 2020.

Políticas Lingüísticas e integración regional: la enseñanza del portugués en Argentina. In: Arnoux, Elvira. Bein, Roberto. (Org.) Peronismo y glotopolítica: intervenciones en el sistema educativo y las academias. Buenos Aires: Biblos, 2019c. p. 107-142.

SCHRÄGLE, Isaure; MENDES, Paula M., Brasil Intercultural Ciclo Avançado, Buenos Aires: Casa do Brasil, 2014. 


\section{Resumo}

\section{Análise glotopolítica de livros didáticos de português na Argentina e de espanhol no Brasil: tensões na representação dos paradigmas verbais e pronominais}

No presente artigo, abordamos o encontro entre o espanhol e o português por meio de livros didáticos de espanhol no ensino médio brasileiro e livros didáticos de português na escuela secundaria argentina. Com base nas políticas linguísticas brasileira e argentina sobre o ensino da língua do país vizinho no ensino médio, realizamos uma análise glotopolítica dos livros didáticos que circularam nas escolas durante o período 2003-2015. Com o objetivo de compreender as ideologias linguísticas em disputa ao sistematizar ambas linguas, elaboramos uma análise comparativa sobre como são abordadas as pessoas do discurso nos livros didáticos. Primeiro, resenhamos diferentes estudos sobre as representações das duas linguas como linguas estrangeiras no Brasil e na Argentina e sobre as assimetrias em relação ao uso dos pronomes e conjugações verbais. Depois, analisamos, de forma contrastiva, os livros didáticos que circularam na Argentina $e$ as cinco coleções aprovadas pelo Programa Nacional do Livro Didático do Brasil de 2012 e 2015. Em conclusão, identificamos duas politicas linguísticas opostas (dirigista, no caso do Brasil, e liberal, no caso da Argentina) nas medidas sobre a elaboração de livros didáticos que tiveram diferentes repercussões nas formas de representar as duas linguas. Em linhas gerais, por um lado, as representações do espanhol consistiram em uma língua rica e diversa; por outro lado, o português foi representado como uma lingua mais homogênea, amarrada a uma tradição prescritiva.

Palavras-chave: Glotopolitica. Mercosul. Linguas estrangeiras. Ensino médio. Livros didáticos.

\section{Abstract \\ Glottopolitical Analysis of Portuguese Textbooks Used in Argentina and Spanish Textbooks Used in Brazil: Tensions in the Representation of Verbal and Pronominal Paradigms}

In this paper we address the encounter of Spanish and Portuguese in both Spanish textbooks used the Brazilian ensino médio, and in Portuguese textbooks used in the Argentine escuela media. We performed a glottopolitical analysis of the learning books used in high school during the period 20032015, considering the Brazilian and Argentine language policies regarding how Spanish and Portuguese are taught in high school as foreign languages. Trying to understand the language ideologies in dispute when systematizing these languages, we developed a comparative analysis on how discourse persons are approached in the books. First, we reviewed different studies regarding the representations of both languages as foreign languages and assessed the asymmetries in relation to the use of pronouns and verb conjugations. Then, we contrasted the books used in Argentina and the five collections approved by the Programa Nacional do Livro Didático in Brazil in 2012 and 2015. In conclusion, we identified that by assuming two opposing language policies (interventionist, in the case of Brazil, and liberal, in the case of Argentina) when preparing the textbooks, the representations of these languages were different. Broadly speaking, Spanish was represented as a richer and more diverse language, while Portuguese was perceived as a more homogeneous language, linked to a prescriptive tradition.

Keywords: Glottopolitics. Mercosur. Foreign languages. High school. Textbooks. 
Virginia Irene Rubio Scola é Doutora em Linguística pela Universidad de Buenos Aires (UBA), mestre em linguística pela Universidade Federal de São Carlos (UFScar) e bacharel em portuguguês pela Universidad Nacional de Rosario. Atualmente, realiza seu pós-doutorado na área da glotopolítcia e ensino de línguas e culturas no Brasil e na Argentina no IRICE-UNR e é professora de linguística e língua portuguesa na Facultad de Humanidades e Artes - UNR, Rosario. Participa do Projeto "Hegemonías y disensos en torno a la regulación del español contemporáneo. Perspectivas nacional, regional y global" (PICT 2017-1794) na UBA, Buenos Aires. 